\title{
Is the vegetative development of the invasive chlorophycean, Caulerpa taxifolia, favored in sediments with a high content of organic matter?
}

\section{Jorge Terrados* and Núria Marbà}

Grupo de Oceanografía Interdisciplinar, IMEDEA (CSICUIB) Instituto Mediterráneo de Estudios Avanzados, Miquel Marqués 21, 07190 Esporles, Mallorca, Islas Baleares, Spain, e-mail: jorge.terrados@uib.es

* Corresponding author

\begin{abstract}
We performed an in situ experiment raising the concentration of organic matter in sediment relative to the natural concentration, and quantified biomass development of the invasive alga, Caulerpa taxifolia, and native C. prolifera. Our objective was to determine whether vegetative development of $C$. taxifolia is favored in sediments with a high content of organic matter. The number of stolon apices and fronds, and the total dry weight of $C$. taxifolia at the end of the experiment increased relative to initial values in the "natural" sediment, while those in the "organic matter-enriched" sediment did not change. As a result, the vegetative development of $C$. taxifolia in the "organic matter-enriched" sediment was marginally lower than that in the sediment with natural concentration of organic matter. The contention that the vegetative development of the invasive $C$. taxifolia is favored in sediments with a high content of organic matter is not sustained. Additionally, we wanted to evaluate whether the presence of an external source of dissolved organic carbon (DOC) would facilitate the survival of Caulerpa taxifolia and $C$. prolifera under conditions unfavorable for biomass development. To this end we performed two laboratory experiments (one under light-saturated and another under light-limited conditions) where we maintained fragments of $C$. taxifolia and $C$. prolifera in the presence of different low molecular weight DOC compounds and assessed the survival of the two species. Mortality of Caulerpa fragments occurred under light-limited conditions only and showed no relationship to the presence of any of the low molecular weight DOC compounds tested. Our results, therefore, do not provide support for the contention that the presence of low molecular weight DOC compounds could contribute to alleviating negative effects associated with light-limited conditions.
\end{abstract}

Keywords: Caulerpa prolifera; Caulerpa taxifolia; growth; sediment organic matter.

\section{Introduction}

The introduction of exotic species is a major driver of biodiversity loss (Sakai et al. 2001). When the introduc- tion of a species modifies the abundance and/or the spatial distribution of native species and, therefore, the structure and function of the ecosystem, this exotic is considered invasive. Eight of the 85 species of macrophytes considered as exotic in the Mediterranean marine flora show an invasive behavior (Boudouresque and Verlaque 2002).

The introduction of the chlorophyte Caulerpa taxifolia (Vahl) C. Agardh in the Mediterranean Sea is an invasion event that has received major attention from the scientific community. Since 1984, C. taxifolia has invaded $131 \mathrm{~km}^{2}$ of bottom surface in six Mediterranean countries (data for 2000, Meinesz et al. 2001). Comparison of invaded and uninvaded Posidonia oceanica L. Delile meadows suggests that $C$. taxifolia may interfere with the vegetative development of the seagrass (Villèle and Verlaque 1995, Dumay et al. 2002), and reduce algal diversity within the invaded communities (Verlaque and Fritayre 1994, Balata et al. 2004).

The monitoring of Caulerpa taxifolia's invasion suggests that Posidonia oceanica meadows with high shoot density are more resistant to $C$. taxifolia invasion than low shoot density meadows (Meinesz et al. 1993, Villèle and Verlaque 1995, Jaubert et al. 1999, 2003), a contention that has received experimental support (Ceccherelli and Cinelli 1999). The invasion of $C$. taxifolia progressed fast in localities affected by urban sewage, where $P$. oceanica had already experienced significant mortality (Chisholm et al. 1997, Jaubert et al. 1999), which suggested that sediment conditions associated with urban pollution (i.e., anoxia, high content of organic matter and hydrogen sulfide) could promote the growth of $C$. taxifolia (Chisholm et al. 1997, Jaubert et al. 2003). Indeed, C. taxifolia is able to acquire inorganic phosphorus and the amino acid valine from the sediment through its rhizoids (Chisholm et al. 1996). Additionally, C. taxifolia photosynthesis did not meet respiratory demand below 24-29 m depth (Chisholm and Jaubert 1997), which is not consistent with the presence of this species at depths up to $99 \mathrm{~m}$ (Belsher and Meinesz 1995), and leads to the suggestion that $C$. taxifolia is able to meet part of its carbon demand through the assimilation of external organic carbon (Chisholm and Jaubert 1997).

Caulerpa prolifera (Forsskal) Lamouroux is present on tropical and sub-tropical coasts, and it is very common in the Mediterranean Sea (Guiry 2006). It has a clonal, coenocytic architecture, similar to that of $C$. taxifolia. C. prolifera usually grows in shallow muddy substrata in sheltered bays, coastal lagoons and port areas, and it is also common on dead mattes of Posidonia oceanica (Meinesz 1980, Ballesteros 1989, Terrados and Ros 1995, Ribera et al. 1997, Vicens 1999, Ballesteros et al. 2001). The habitat of the native C. prolifera, therefore, appears similar to those where the invasion of $C$. taxifolia 
may be favored, i.e., muddy, anoxic sediments with high content of organic matter.

The first goal of this study was to evaluate whether sediments with an increased concentration of organic matter would provide a better substratum for the vegetative development of Caulerpa taxifolia than sediments with "natural" concentrations of organic matter. To this end we performed an in situ experiment where we increased the content of organic matter of the sediment relative to natural concentrations, and assessed the development of biomass of the invasive C. taxifolia and the native $C$. prolifera.

External organic carbon has not been considered to play a significant role in the total carbon balance of macroalgae given the low concentration of dissolved organic carbon in sea water (Kremer 1981). However, the organic matter content of marine sediments can be high (Bourcier 1989, Delgado et al. 1999, Ruiz et al. 2001), leading to high pools of dissolved organic carbon (DOC) in sediment pore water (Burdige and Homstead 1994, Köster and Meyer-Reil 2001). External glucose and acetate at mM concentration allowed Ulva lactuca L. to maintain an intact photosynthetic apparatus and survive during long periods of darkness or low-light in laboratory conditions (Markager and Sand-Jensen 1990). Hence, it can be surmised that the presence of external sources of DOC associated with sediments enriched with organic matter might facilitate the survival of other macroalgae under conditions unfavorable to biomass development.

The second goal of this study was to determine whether the presence of an external source of DOC would facilitate the survival of Caulerpa taxifolia and C. prolifera under conditions unfavorable to biomass development (light limitation). We performed two laboratory experiments (one under light-saturated and another under lightlimited conditions) where we maintained fragments of C. taxifolia and C. prolifera in the presence of different low molecular weight DOC compounds and assessed the survival of the two species. An external DOC-facilitated survival of $C$. taxifolia under light-limited conditions could provide, partly at least, a mechanistic explanation for the fast progression of the invasion of this species in sediments affected by urban pollution with dead or dying seagrasses (Chisholm et al. 1997, Jaubert et al. 2003).

\section{Materials and methods}

Caulerpa taxifolia and C. prolifera material used in the experiments was collected haphazardly during the summer of 2004 by SCUBA divers in Cala D'Or (N 39 $22.164^{\prime}$, E $3^{\circ} 13.887^{\prime}$ ), a small bay in the southeast of Mallorca island, where C. taxifolia has been present since 1992 (Meinesz et al. 2001). The "organic matter-enriched" sediment was prepared two months before the initiation of the in situ experiment by mixing natural sediment collected in the submerged part of a beach adjacent to the Posidonia oceanica meadow where the experiment was to be performed with an equal volume of $C$. taxifolia and $P$. oceanica leaves collected in the $P$. oceanica meadow, and maintaining the mixture at room temperature in the laboratory until the start of the experiment. Natural sediment was collected at the same time and kept in similar conditions. Three samples of each type of sediment were collected, dried at $60^{\circ} \mathrm{C}$ over $48 \mathrm{~h}$, weighed, and burned at $450^{\circ} \mathrm{C}$ for $4 \mathrm{~h}$ to estimate the amount of organic matter as percentage of sediment dry weight (DW). Additional samples of sediment were collected and pore water was extracted by forcing $\mathrm{N}_{2}$ to flow through the sample. Five-ml of Whatman ${ }^{\circledR}$ (Maidstone, UK) GF/C filtered pore water were fixed with $50 \mu \mathrm{l}$ of $\mathrm{NaOH}$ $1 \mathrm{M}$ and $50 \mu \mathrm{l}$ of $\mathrm{Zn}\left(\mathrm{CH}_{3}-\mathrm{COO}\right)_{2} 1 \mathrm{M}$ and frozen for later sulfide analysis (Cline 1969).

The day before the initiation of the in situ experiment, Caulerpa taxifolia and C. prolifera were collected, and the fragments to be planted in plant window boxes were selected. Each selected fragment contained at least one stolon apex. The numbers of fronds and stolon apices of each fragment were counted, fresh weights were determined, and the fragments were haphazardly assigned to each treatment and replicate. Sixty-three fronds of C. taxifolia and 59 fronds of $C$. prolifera additional to those of the fragments were measured to estimate the average initial length of the fragment fronds of each species. Nineteen additional fragments of both C. taxifolia and $C$. prolifera, encompassing the range of sizes of those used in the experiment were selected, weighed fresh, and dried at $60^{\circ} \mathrm{C}$ over $48 \mathrm{~h}$ to estimate dry weight and to obtain a fresh weight-dry weight ratio for the fragments of each species.

The in situ experiment started on 8 July 2004 by filling 12 plastic plant window boxes (internal dimensions: $11.5 \times 37 \times 13 \mathrm{~cm})$ with sediment $(6$ with "natural" sediment and 6 with "organic matter-enriched" sediment) and planting in them fragments of either Caulerpa taxifolia or $C$. prolifera with the aid of 2-3 plastic cable ties placed around the stolon of each fragment. Care was taken so that each plant window box contained a similar number of fragments, stolon apices and fronds, and algal fresh weights. Thus, the number of replicates for each combination of sediment type and Caulerpa species was 3. The plant window boxes were placed in a sand gap at a depth of $6 \mathrm{~m}$ in a Posidonia oceanica meadow invaded by $C$. taxifolia; they were buried in the sand so that the brims of the boxes were at the level of the sediment surface.

The in situ experiment ended on 20 September 2004 when the plant window boxes were dug out and the extant algal material in each of them was placed inside a plastic bag and transported to the laboratory. The plant window boxes were transported to the laboratory and a sediment sample was collected from each to estimate the content of organic matter and the concentration of sulfide in sediment pore water. The numbers of fronds and stolon apices present in each window box at the end of the experiment were counted, and the lengths of the fronds were measured (exactly 30 fronds were measured in those window boxes in which the number of extant fronds was $>30$ ). Total fresh weight of extant Caulerpa in each window box was determined and dried at $60^{\circ} \mathrm{C}$ over $48 \mathrm{~h}$ to estimate its dry weight.

The content of organic matter of the sediment increased ( $t$-test, $p<0.05)$ from $1.7 \pm 0.07(\mathrm{SE}) \%$ of sediment DW for the "natural" sediment to $3.5 \pm 0.37$ (SE)\% 
of sediment DW for the "organic matter-enriched" sediment. Sulfide concentration in sediment pore water was higher ( $t$-test, $p<0.05$ ) in the "organic matter-enriched" sediment $[46.8 \pm 19.41$ (SE) $\mu \mathrm{M}]$ than in the "natural" sediment $[0.1 \pm 0.06(\mathrm{SE}) \mu \mathrm{M}]$. The content of organic matter at the end of the in situ experiment was still higher $(t$-test, $\mathrm{p}<0.05)$ in the organic matter-enriched sediment $[2.3 \pm 0.26(\mathrm{SE}) \% \mathrm{DW}]$ than in the natural sediment $[1.6 \pm 0.18(\mathrm{SE}) \% \mathrm{DW}]$, but the concentrations of sulfide in sediment pore water were similar ( $t$-test, $p>0.05$ ) [natural: $1.4 \pm 0.66$ (SE) $\mu \mathrm{M}$; organic matter-enriched: 0.9 \pm 0.39 (SE) $\mu \mathrm{M}$ ].

The significance of differences in the number of stolon apices and fronds, and both the fresh and dry weights of Caulerpa between window boxes filled with natural sediment and those filled with organic matter-enriched sediment were tested using a $t$-test for independent samples. Differences between initial and final number of stolon apices and fronds, average frond length, and total fresh and dry weight in natural and organic matterenriched sediments were tested using a $t$-test for dependent samples. Finally, differences between natural and organic matter-enriched sediment in the number of stolon apices and fronds, average frond length, and total fresh and dry weight at the end of the experiment were tested using a $t$-test for independent samples.

The Caulerpa material to be used in the laboratory experiments was collected on two different days ( 9 July 2004 for the light-saturated conditions, 20 September 2004 for the light-limited conditions) and it was maintained at $25^{\circ} \mathrm{C}$ and a $14 \mathrm{~h}$ light: $10 \mathrm{~h}$ darkness photoperiod until fragments of fronds were produced. The fragments of $C$. taxifolia were obtained by cutting the apical part of fronds [fragment length: $3.8 \pm 0.1$ (SE) cm] while those of $C$. prolifera were produced by cutting the frond stalk near its insertion in the stolon [i.e., the fragments contained both the blade and the stalk; fragment length: $7.4 \pm 0.1$ (SE) cm]. We used full fronds of $C$. prolifera as previous studies showed that 4-cm-long fragments of this species, which included only the blade, did not survive fragmentation while fragments of the same length but including the stalk had 100\% survivorship (Smith and Walters 1999). Large-size and persistent branching of $C$. taxifolia fronds at the tips prevented us from using fragments of length similar to those of $C$. prolifera. Previous studies, however, showed $100 \%$ survivorship of C. taxifolia fragments of only $2 \mathrm{~cm}$ length (Smith and Walters 1999). Ten additional fragments of each species similar to those used in the experiment were cut and dried at $60^{\circ} \mathrm{C}$ over $48 \mathrm{~h}$ to calculate a frond length:dry weight ratio and estimate the initial dry weight of each fragment. Each fragment was placed inside a 50$\mathrm{ml}$ polyethylene culture tube containing $10 \mathrm{ml}$ of dry beach sand and filled to the 50-ml level with seawater (seawater and sand collected from the same location as the algal material).

One $\mathrm{ml}$ of either sodium acetate, sodium lactate, D-glucose, L-glutamic acid, $\beta$-alanine, L-alanine, glycine, or L-serine concentrated solutions was injected into the sand phase of each culture tube to achieve a nominal concentration of $294 \mu \mathrm{M}$ in pore water (if all the injected solution remained within sand interstices). We cannot exclude the possibility that a fraction of the injected solution might have moved to the water phase. If all the injected solution had moved to the water phase, the nominal concentration of the added compound would be $44 \mu \mathrm{M}$. The amino acids chosen were those reported to be most abundant in Posidonia oceanica sediments, where total dissolved free amino acid concentration varies between $105 \mu \mathrm{M}$ and $436 \mu \mathrm{M}$ in interstitial water, while the concentration in the water column is lower than $2 \mu \mathrm{M}$ (Jorgensen et al. 1981). In an additional treatment, we injected $1 \mathrm{ml}$ of seawater to control for experimental manipulations. Seawater inside the culture tubes was changed weekly, and the different organic carbon compounds were supplied again according to treatments. The initial number of replicates for each treatment varied between 7 and 8 .

Caulerpa fragments were maintained for 18 days (lightsaturated conditions) or 25 days (light-limited conditions) at $25^{\circ} \mathrm{C}$, and each culture tube was manually agitated every 2-3 days for $15 \mathrm{~s}$ to break gradients in the water phase. Photon flux density inside the incubation chamber varied between 187 and $298 \mu \mathrm{mol} \mathrm{m} \mathrm{m}^{-2} \mathrm{~s}^{-1}$, depending on the particular position. Saturation photon irradiance for C. taxifolia photosynthesis varies between 44 and $166 \mu \mathrm{mol} \mathrm{m}^{-2} \mathrm{~s}^{-1}$ (Gacia et al. 1996, Chisholm et al. 2000), while that of $C$. prolifera varies between 11 and $112 \mu \mathrm{mol}$ $\mathrm{m}^{-2} \mathrm{~s}^{-1}$ (Terrados and Ros 1992). Light-saturated and light-limited conditions conditions were achieved by maintaining the fragments under $14 \mathrm{~h}$ light: $10 \mathrm{~h}$ dark and $1.5 \mathrm{~h}$ light:22.5 h dark photoperiod regimes, respectively. At the end of the experiments the fragments were dried at $60^{\circ} \mathrm{C}$ for $48 \mathrm{~h}$ to estimate their dry weights. The specific growth rate (SGR) of each Caulerpa fragment (i.e., the average instantaneous rate of production of mass relative to the initial mass of the fragment) was calculated as

$S G R=\frac{W_{f}-W_{0}}{\left(T_{f}-T_{0}\right) W_{0}}$

where $W_{0}$ and $W_{f}$ are the initial and final dry weights of the fragment, respectively, and $\left(T_{\mathrm{f}}-T_{0}\right)$ is the duration of the experiment. Differences in SGR between Caulerpa fragments in light-saturated and light-limited conditions were tested using 2-way ANOVAs with "species" and "external organic carbon" as fixed factors. Prior to analysis the homogeneity of variances of data was tested using the Bartlett's test.

\section{Results}

The number of stolon apices and fronds, and the total fresh weight and dry weight per plant window box of both Caulerpa taxifolia and C. prolifera at the initiation of the in situ experiment were not different between the natural sediment and the organic matter-enriched sediment ( $t$-test for independent samples; Figure 1, Table 1). The number of stolon apices and fronds, and total dry weight of C. taxifolia in natural sediments tended to increase from the initiation to the end of the experiment (Figure 1a,c,e, Table 1). However, these variables did not change 

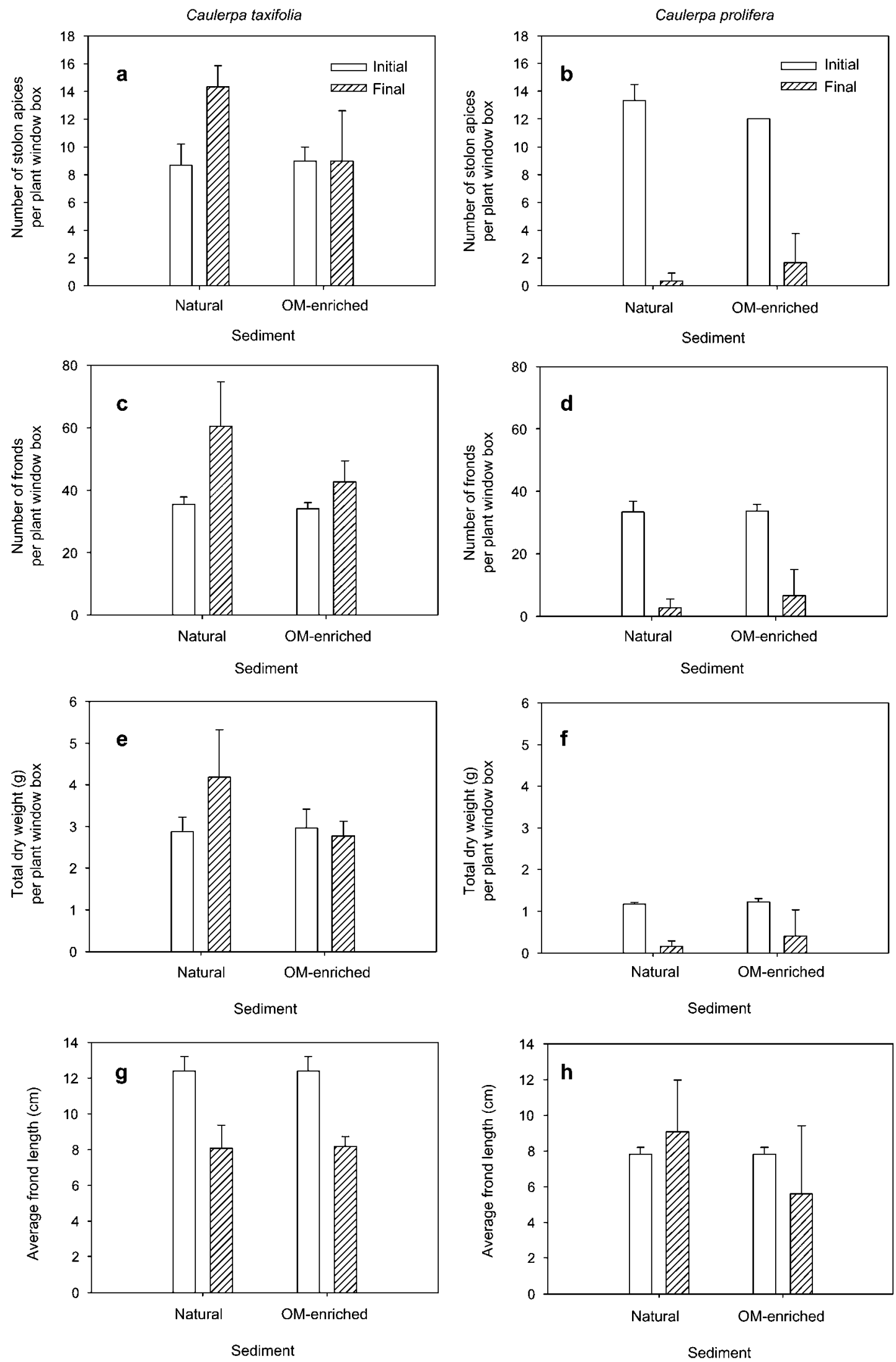

Figure 1 Caulerpa taxifolia and C. prolifera: number of stolon apexes (a, b), fronds (c, d), and total dry weight (e, f) per plant window box, and frond length $(\mathrm{g}, \mathrm{h})$ at the beginning and end of a 74-day growth period in "natural" and "organic matter-enriched" sediment. Error bars represent mean $+1 \mathrm{SD}$. $\mathrm{OM}=$ organic matter. 
芦年茴

il il il

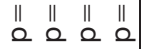

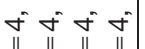

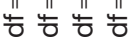
ลิจ III II II II in the organic matter-enriched sediment. Hence, the number of stolon apices and fronds, and total dry weight of $C$. taxifolia at the end of the experiment tended to be lower in the organic matter-enriched sediment than in the natural sediment. The average frond length of $C$. taxifolia decreased from $12.4 \mathrm{~cm}$ at the beginning of the experiment to $8.2 \mathrm{~cm}$ at the end, but there were no differences between natural and organic matter-enriched sediment at any time (Figure 1g, Table 1).

Caulerpa prolifera experienced large losses of biomass during the in situ experiment, both in natural and organic matter-enriched sediments (Figure 1f), and the number of stolon apices and fronds, and total dry weight were not different between the two sediment types at the beginning and end of the experiment (Figure 1b,d,f, Table 1). The average length of $C$. prolifera fronds was not different between the two types of sediments either (Figure 1h).

Mortality of Caulerpa fragments maintained in the laboratory occurred under light-limited conditions only. The mortality of $C$. prolifera fragments (two of seven replicates in the $\beta$-alanine and L-alanine treatments, and one of seven replicates in the control, D-glucose, and L-glutamic acid treatments) was accompanied by indications of gametogenesis (cf. Meinesz 1979a, Clifton and Clifton 1999). Mortality of C. taxifolia fragments occurred in only two of seven replicates in the D-glucose treatment.

The SGR of the fragments of Caulerpa prolifera under light-saturated conditions was higher than that of $C$. taxifolia (Figure 2, Table 2), but there was no significant difference in fragment SGRs among the various low molecular weight DOC compounds. When light availability was reduced to only $1.5 \mathrm{~h}$ per day, fragments of C. prolifera experienced a net loss of mass, resulting in negative values of SGR while values for $C$. taxifolia were low-positive or negative (Figure 3). Again, the presence of different low molecular weight DOC compounds did not seem to affect the SGR of the fragments (Figure 3, Table 2).

\section{Discussion}

Our results do not support the contention that sediments with a higher content of organic matter than those with natural concentrations provide a more favorable substratum for the vegetative development of Caulerpa taxifolia. Indeed, the number of stolon apices and fronds, and total dry weight at the end of the in situ experiment increased relative to initial values in the natural sediment, while those in the organic matter-enriched sediment did not change. The final vegetative development attained by C. taxifolia in the organic matter-enriched sediment was marginally lower than that in the natural sediment. The concentration of dissolved sulfide in pore water was higher in organic matter-enriched sediment than in natural sediment at the initiation of the experiment and this high concentration of sulfide might have affected $C$. taxifolia growth negatively, for sulfide is toxic to marine macrophytes (Goodman et al. 1995, Erskine and Koch 2000, Holmer and Bondgaard 2001, Koch and Erskine 2001, Halun et al. 2002). C. prolifera experienced high biomass losses in both types of sediments, which prevents us 


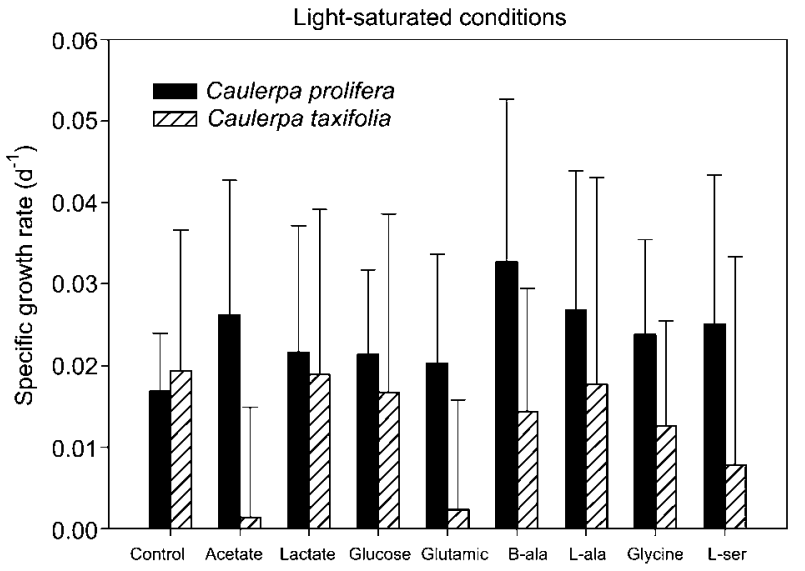

Figure 2 Caulerpa taxifolia and C. prolifera: specific growth rates of fragments maintained in the presence of different low molecular weight dissolved organic carbon compounds under light-saturated conditions.

Error bars represent mean $+1 \mathrm{SD}$.

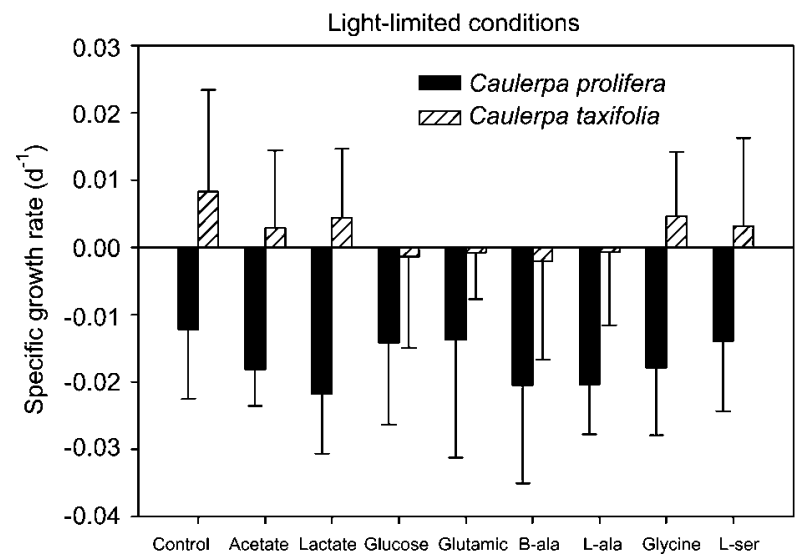

Figure 3 Caulerpa taxifolia and C. prolifera: specific growth rates of fragments maintained in the presence of different low molecular weight dissolved organic carbon compounds under light-limited conditions.

Error bars represent means $+1 \mathrm{SD}$.

Table 2 Caulerpa taxifolia and C. prolifera: analysis of variance of the specific growth rates of fragments growing in the presence of different low molecular weight DOC compounds under light-saturated and light-limited conditions.

\begin{tabular}{llrl}
\hline Conditions & Source of variation & df & MS \\
\hline Light-saturated & & & \\
& Species & 1 & $0.0043^{\star}$ \\
& Carbon source & 8 & $0.0002^{\text {ns }}$ \\
& S $\times$ C & 8 & $0.0003^{\text {ns }}$ \\
& Error & 120 & 0.0006 \\
& Total & 137 &
\end{tabular}

Light-limited

\begin{tabular}{lrl} 
Species & 1 & $0.0097^{\star \star *}$ \\
Carbon source & 8 & $0.0001^{\text {ns }}$ \\
S $\times$ C & 8 & $0.0001^{\text {ns }}$ \\
Error & 100 & 0.0002 \\
Total & 117 & \\
\hline
\end{tabular}

*: $p<0.05 ;{ }^{* * *}: p<0.001$; ns: not significant. from determining whether the vegetative development of this species is promoted in sediments with high content of organic matter.

Oxygen measurements in the rhizosphere of Caulerpa taxifolia maintained in aquaria suggest that the rhizoids of this species might release oxygen to the sediment at least during daylight hours (cf. Chisholm and Moulin 2003). However, the same study provides indirect evidence of the release of photosynthetic products to the sediment and of the promotion of sulfate reduction and nitrogen fixation in the rhizosphere of $C$. taxifolia. The large reduction in the concentration of sulfide in the pore water of the organic matter-enriched sediment during the in situ experiment might have been driven by the release of oxygen by $C$. taxifolia rhizoids, but sulfide diffusion driven by a strong concentration gradient and chemical oxidation might have been a significant process too, for the reduction in sulfide concentration in pore water also occurred in the sediment where $C$. prolifera was planted and decayed rapidly.

The large mass losses that Caulerpa prolifera experienced in both natural and organic matter-enriched sediments suggest that this species was more sensitive to the experimental manipulations than $C$. taxifolia. The experiment was performed between July and October, that is, within the vegetative growth period of both species (Meinesz 1979b, Meinesz et al. 1995, Terrados and Ros 1995). High sensitivity to the experimental manipulations, which involved mechanical fragmentation of thalli and planting in the sediment, could be interpreted as lower viability of thallus fragments produced by mechanical force. The viability of the fragments of $C$. prolifera is lower than those of C. taxifolia. Lower viability of thallus fragments produced by mechanical fragmentation, such as that produced naturally by waves and currents, suggests lower dispersal and invasive capacities in C. prolifera. Indeed, fronds of this species are less robust when fragmented mechanically than those of C. taxifolia (Smith and Walters 1999).

External glucose and acetate at $\mathrm{mm}$ concentrations allow Ulva lactuca to maintain an intact photosynthetic apparatus and survive during 41 days of darkness or low-light laboratory conditions (Markager and Sand-Jensen 1990). Although the relevance to field conditions is not clear, these observations suggest the importance of organic carbon uptake in maintaining an intact photosynthetic apparatus during light-limited conditions, rather than as a source of carbon for growth (op. cit.). Our results show that the presence of low molecular weight DOC compounds external to Caulerpa taxifolia and C. prolifera fragments did not promote the growth of specimens maintained in the laboratory under light-saturated and light-limited conditions. The SGRs of fragments with no DOC compounds added (controls) were not different from the SGRs of fragments exposed to the different DOC compounds. The amount of carbon added to the culture tubes during the experiments was only $3 \%$ to $13 \%$ of the average carbon gain of C. prolifera fragments in light-saturated conditions, and $4 \%$ to $18 \%$ of the average carbon loss in light-limited conditions (considering an average ash content of $13.5 \%$ of DW and an average carbon content of $33.6 \%$ of DW for C. prolifera; 
cf. Terrados and Ros 1995). These calculations suggest that the amount of carbon added might not have been enough to increase fragment growth significantly had it been completely assimilated by $C$. prolifera fragments, and the same likely holds for $C$. taxifolia.

Mortality of Caulerpa fragments occurred under lightlimited conditions only and showed no relationship to the presence of any of the low molecular weight DOC compounds. Mortality of $C$. prolifera fragments was associated with the morphological changes that occur when this species reproduces sexually (Meinesz 1979a, Clifton and Clifton 1999) and it occurred in both control fragments and in fragments exposed to some of the DOC compounds. In the case of C. taxifolia, two events of fragment mortality were recorded and only when D-glucose was present. These $C$. taxifolia mortality events were not associated with any morphological change that could be linked to sexual reproduction, as described for the genus Caulerpa (Goldstein and Morrall 1970, Clifton and Clifton 1999, Žuljević and Antolić 2000). Our results, therefore, do not provide support for the hypothesis that the presence of low molecular weight DOC compounds could contribute to alleviating negative effects associated with light-limited conditions, as has been suggested for Ulva lactuca (Markager and Sand-Jensen 1990).

Our experiments showed, however, different patterns in the response of Caulerpa taxifolia and C. prolifera to the experimental conditions. First, the SGRs of the fragments of $C$. prolifera were higher than those of $C$. taxifolia under light-saturated conditions. Second, the SGRs of C. prolifera fragments under light-limited conditions were negative and similar in magnitude to the values recorded under light-saturated conditions, while the SGRs of C. taxifolia fragments under light-limited conditions were minimal. This pattern was not affected by the presence of low-molecular weight DOC compounds. Could this be interpreted as $C$. taxifolia being more resistant to lightlimiting conditions than $C$. prolifera? Previous knowledge on the influence of light availability on the photosynthetic rate of both species does not suggest this to be the case, since compensation irradiance $\left(\mathrm{I}_{\mathrm{c}}\right)$ and saturation irradiance $\left(\mathrm{I}_{\mathrm{k}}\right)$ of $\mathrm{C}$. taxifolia at water temperatures above $20^{\circ} \mathrm{C}$ vary between 6 and $30 \mu \mathrm{mol} \mathrm{m} \mathrm{m}^{-2} \mathrm{~s}^{-1}$ and 44 and $309 \mu \mathrm{mol} \mathrm{m} \mathrm{m}^{-2} \mathrm{~s}^{-1}$, respectively (Gacia et al. 1996, Chisholm and Jaubert 1997, Chisholm et al. 2000), while $I_{c}$ of C. prolifera varies between 5 and $11 \mu \mathrm{mol} \mathrm{m} \mathrm{m}^{-2} \mathrm{~s}^{-1}$ and $\mathrm{I}_{\mathrm{k}}$ varies between 19 and $97 \mu \mathrm{mol} \mathrm{m}{ }^{-2} \mathrm{~s}^{-1}$ (Terrados and Ros 1992). Given that the Caulerpa material used in the lightsaturated and light-limited conditions was collected on different dates, that the experiments were not performed simultaneously, and that they were not repeated, it is not possible to determine whether the different patterns of response of the two species are driven by speciesspecific differences (i.e., the contention that C. taxifolia is more resistant to light-limited conditions than $C$. prolifera) or by fragment-specific differences (i.e., a higher amount of photosynthetic products stored inside the C. taxifolia fragments collected in September compared to that of fragments collected in July).

In summary, the results of the experiments performed do not provide support to the hypothesis that vegetative development of Caulerpa taxifolia is favored in sediments with high loads of organic matter. Hence, the hypothesized higher invasive capacity of C. taxifolia in these types of substrata is not sustained. The presence of low molecular weight DOC compounds does not seem to affect the viability of fragments of either of the species under light-limited conditions. The patterns of response in the in situ experiment suggest that the invasive $C$. taxifolia might be more resistant to mechanical fragmentation than native $C$. prolifera, and this might be of relevance to the differing invasive capabilities.

\section{Acknowledgements}

This study was funded by Plan Nacional de I+D+I (2000-2003), Ministerio de Ciencia y Tecnología of Spain (research project REN2002-00701/MAR). Marina de Cala D'Or (Cala D'Or, Santanyi) kindly made available its harbor facilities for executing this study. We thank S. Agustí for providing access to the incubation chamber, C. Duarte and J.C. Alonso for their collaboration with the sulfide analysis of sediment pore water, and V. Riera and E. Varela for help in the laboratory and the field, respectively.

\section{References}

Balata, D., L. Piazzi and F. Cinelli. 2004. A comparison among assemblages in areas invaded by Caulerpa taxifolia and $C$. racemosa on a subtidal Mediterranean rocky bottom. P. S. Z. N. I: Mar. Ecol. 25: 1-13.

Ballesteros, E. 1989. Els herbeis de Caulerpa prolifera (Forsskal) Lamouroux de la Badia de Pollenca (Mallorca, Mediterrania Occidental). Boll. Soc. Hist. Nat. Balears 33: 99-116.

Ballesteros, E., S. Pinedo and M. Garcia. 2001. Monitoring of a shallow water population of Caulerpa taxifolia (Vahl) C. Agardh in Porto Petro (Mallorca, Balearic Islands): data from 1998. In: (V. Gravez et al., eds) Fourth International Workshop on Caulerpa taxifolia. GIS Posidonie, Marseille. pp. 92-99.

Belsher, T. and A. Meinesz. 1995. Deep-water dispersal of the tropical alga Caulerpa taxifolia introduced into the Mediterranean. Aquat. Bot. 51: 163-169.

Boudouresque, C.F. and M. Verlaque. 2002. Biological pollution in the Mediterranean Sea: invasive versus introduced macrophytes. Mar. Poll. Bull. 44: 32-38.

Bourcier, M. 1989. Regression des herbiers à Posidonia oceanica (L.) Delile, à l'Est de Marseille, sous l'action conjuguee des activites humaines et des modifications climatiques. In: (C.F. Boudouresque et al., eds) International Workshop on Posidonia beds. GIS Posidonie, Marseille. pp. 287-292.

Burdige, D.J. and J. Homstead. 1994. Fluxes of dissolved organic carbon from Chesapeake Bay sediments. Geochim. et Cosmochim. Acta 58: 3407-3424.

Ceccherelli, G. and F. Cinelli. 1999. Effects of Posidonia oceanica canopy on Caulerpa taxifolia size in a north-western Mediterranean bay. J. Exp. Mar. Biol. Ecol. 240: 19-36.

Chisholm, J.R.M. and J.M. Jaubert. 1997. Photoautotrophic metabolism of Caulerpa taxifolia (Chlorophya) in the NW Mediterranean. Mar. Ecol. Prog. Ser. 153: 113-123.

Chisholm, J.R.M. and P. Moulin. 2003. Stimulation of nitrogen fixation in refractory organic sediments by Caulerpa taxifolia (Chlorophyta). Limnol. Oceanogr. 48: 787-794.

Chisholm, J.R.M., C. Dauga, E. Ageron, P.A.D. Grimont and J.M. Jaubert. 1996. Roots in mixotrophic algae. Nature 381: 382.

Chisholm, J.R.M., M. Marchioretti and J.M. Jaubert. 2000. Effect of low water temperature on metabolism and growth of a subtropical strain of Caulerpa taxifolia (Chlorophyta). Mar. Ecol. Prog. Ser. 201: 189-198. 
Chisholm, J.R.M., F.E. Fernex, D. Mathieu and J.M. Jaubert. 1997. Wastewater discharge, seagrass decline and algal proliferation on the Côte d'Azur. Mar. Poll. Bull. 34: 78-84.

Clifton, K.E. and L.M. Clifton. 1999. The phenology of sexual reproduction by green algae (Bryopsidales) on Caribbean coral reefs. J. Phycol. 35: 24-34.

Cline, J.D. 1969. Spectrophotometric determination of hydrogen sulfide in natural waters. Limnol. Oceanogr. 14: 454-458.

Delgado, O., J.M. Ruiz, M. Pérez, J. Romero and E. Ballesteros. 1999. Effects of fish farming on seagrass (Posidonia oceanica) in a Mediterranean bay: seagrass decline after organic loading cessation. Oceanol. Acta 22: 109-117.

Dumay, O., C. Fernandez and G. Pergent. 2002. Primary production and vegetative cycle in Posidonia oceanica when in competition with the green algae Caulerpa taxifolia and Caulerpa racemosa. J. Mar. Biol. Assoc. U.K. 82: 379-387.

Erskine, J.M. and M.S. Koch. 2000. Sulfide effects on Thalassia testudinum carbon balance and adenylate energy charge. Aquat. Bot. 67: 275-285.

Gacia, E., C. Rodríguez-Prieto, O. Delgado and E. Ballesteros. 1996. Seasonal light and temperature responses of Caulerpa taxifolia from the northwestern Mediterranean. Aquat. Bot. 53: $215-225$

Goldstein, M. and S. Morrall. 1970. Gametogenesis and fertilization in Caulerpa. Ann. NY Acad. Sci. 175: 660-672.

Goodman, J.L., K.A. Moore and W.C. Dennison. 1995. Photosynthetic responses of eelgrass (Zostera marina L.) to light and sediment sulfide in a shallow barrier island lagoon. Aquat. Bot. 50: 37-47.

Guiry, M.D. 2006. AlgaeBase version 4.1. World-wide electronic publication, National University of Ireland, Galway. http:// www.algaebase.org; searched on 07 July 2006.

Halun, Z., J. Terrados, J. Borum, L. Kamp-Nielsen, C.M. Duarte and M.D. Fortes. 2002. Experimental evaluation of the effects of siltation-derived changes in sediment conditions on the Philippine seagrass Cymodocea rotundata. J. Exp. Mar. Biol. Ecol. 279: 73-87.

Holmer, M. and E.J. Bondgaard. 2001. Photosynthetic and growth response of eelgrass to low oxygen and high sulfide concentrations during hypoxic events. Aquat. Bot. 70: 29-38.

Jaubert, J.M., J.R.M. Chisholm, D. Ducrot, H.T. Ripley, L. Roy and G. Passeron-Seitre. 1999. No deleterious alterations in Posidonia beds in the Bay of Menton (France) eight years after Caulerpa taxifolia colonization. J. Phycol. 35: 1113-1119.

Jaubert, J.M., J.R.M. Chisholm, A. Minghelli-Roman, M. Marchioretti, J.H. Morrow and H.T. Ripley. 2003. Re-evaluation of the extent of Caulerpa taxifolia development in the northern Mediterranean using airborne spectrographic sensing. Mar. Ecol. Prog. Ser. 263: 75-82.

Jorgensen, N.O.G., T.H. Blackburn, K. Henriksen and D. Bay. 1981. The importance of Posidonia oceanica and Cymodocea nodosa as contributors of free amino acids in water and sediment of seagrass beds P.S.Z.N.I: Mar. Ecol. 2: 97-112.

Kremer, B.P. 1981. Carbon metabolism. In: (C.S. Lobban and M.J. Wynne, eds) The biology of seaweeds. Blackwell Scientific Publications, Oxford. pp. 493-533.

Koch, M.S. and J.M. Erskine. 2001. Sulfide as a phytotoxin to the tropical seagrass Thalassia testudinum: interactions with light, salinity and temperature. J. Exp. Mar. Biol. Ecol. 266: 81-95.

Köster, M. and L.-A. Meyer-Reil. 2001. Characterization of carbon and microbial biomass pools in shallow water coastal sediments of the southern Baltic Sea (Nordrügensche Bodden). Mar. Ecol. Prog. Ser. 214: 25-41.

Markager, S. and K. Sand-Jensen. 1990. Heterotrophic growth of Ulva lactuca (Chlorophyceae). J. Phycol. 26: 670-673.
Meinesz, A. 1979a. Contribution à l'étude de Caulerpa prolifera (Forsskal) Lamouroux (Chlorophycée-Caulerpale). II. La reproduction sexueé sur les côtes occidentales de la Méditerranée. Bot. Mar. 22: 117-121.

Meinesz, A. 1979b. Contribution à l'étude de Caulerpa prolifera (Forsskal) Lamouroux (Chlorophycée-Caulerpale). III. Biomasse et productivité primaire dans une station des côtes continentales françaises de la Méditerranée. Bot. Mar. 22: 123-127.

Meinesz, A. 1980. Contribution à l'etude des Caulerpales (Chlorophytes). PhD thesis, University of Nice. pp. 262.

Meinesz, A., J. de Vaugelas, B. Hesse and X. Mari. 1993. Spread of the introduced tropical green alga Caulerpa taxifolia in northern Mediterranean waters. J. Appl. Phycol. 5: 141-147.

Meinesz, A., L. Benichou, J. Blachier, T. Komatsu, R. Lemée, H. Molenaar and X. Mari. 1995. Variations in the structure, morphology and biomass of Caulerpa taxifolia in the Mediterranean Sea. Bot. Mar. 38: 499-508.

Meinesz, A., T. Belsher, T. Thibaut, B. Antolic, K.B. Mustapha, C.F. Boudouresque, D. Chiaverini, F. Cinelli, J.M. Cottalorda, A. Djellouli, A. El Abed, C. Orestano, A. Grau, L. Ivesa, A. Jacklin, H. Langar, E. Massuti-Pascual, A. Peirano, L. Tunesi, J. Vaugelas, N. Zavodnik and A. Zuljevic. 2001. The introduced green alga Caulerpa taxifolia continues to spread in the Mediterranean. Biol. Invas. 3: 201-210.

Ribera, G., M. Coloreu, C. Rodríguez-Prieto and E. Ballesteros. 1997. Phytobenthic assemblages of Addaia Bay (Menorca, Western Mediterranean): composition and distribution. Bot. Mar. 40: 523-532

Ruiz, J.M., M. Pérez and J. Romero. 2001. Effects of fish farm loadings on seagrass (Posidonia oceanica) distribution, growth and photosynthesis. Mar. Poll. Bull. 42: 749-760.

Sakai, A.K., F.W. Allendorf, J.S. Holt, D.M Lodge, J. Molofsky, K.A. With, S. Baughman, R.J. Cabin, J.E. Cohen, N.C. Ellstrand, D.E. McCauley, P. O'Neil, I.M. Parker, J.N. Thompson and S.G. Weller. 2001. The population biology of invasive species. Ann. Rev. Ecol. Syst. 32: 305-332.

Smith, C.M. and L.J. Walters. 1999. Fragmentation as a strategy for Caulerpa species: fates of fragments and implications for management of an invasive weed. P.S.Z.N.I: Mar. Ecol. 20: 307-319.

Terrados, J. and J.D. Ros. 1992. The influence of temperature on seasonal variation of Caulerpa prolifera (Forsskal) Lamouroux photosynthesis and respiration. J. Exp. Mar. Biol. Ecol. 162: 199-212.

Terrados, J. and J.D. Ros. 1995. Temperature effects on photosynthesis and depth distribution of the seagrass Cymodocea nodosa (Ucria) Ascherson in a mediterranean coastal lagoon: the Mar Menor (SE Spain). P.S.Z.N.I: Mar. Ecol. 16: 133-144.

Verlaque, M. and P. Fritayre. 1994. Modifications des communautés algales méditerranéenes en présence de l'algue envahissante Caulerpa taxifolia (Vahl) C. Agardh. Oceanol. Acta 17: 659-672.

Vicens, M.A. 1999. Distribució i estat biològic de les comunitats de macrófits bentónics de Portocolom (Mallorca). Detectada la presència de Caulerpa taxifolia (Vahl) C. Agardh. Boll. Soc. Hist. Nat. Balears 42: 179-186.

Villèle, X. de and M. Verlaque. 1995. Changes and degradation in a Posidonia oceanica bed invaded by the introduced tropical alga Caulerpa taxifolia in the north-western Mediterranean. Bot. Mar. 38: 79-87.

Žuljević, A. and B. Antolić. 2000. Synchronous release of male gametes of Caulerpa taxifolia (Caulerpales, Chlorophyta) in the Mediterranean Sea. Phycologia 39: 157-159.

Received 24 April, 2006; accepted 26 July, 2006 